\title{
Retraction Note to: Silibinin ameliorates arsenic induced nephrotoxicity by abrogation of oxidative stress, inflammation and apoptosis in rats
}

\author{
S. Milton Prabu ${ }^{1} \cdot$ M. Muthumani ${ }^{1}$
}

Published online: 7 July 2021

(c) Springer Nature B.V. 2021

\section{Retraction to: Molecular Biology Reports (2012) 39:11201-11216 https://doi.org/10. 1007/s11033-012-2029-6}

The editors have retracted this article. Concerns were raised regarding a number of figures, specifically:

- Figures 5A, 6A, 7A and 7D appear to be part of one sample;

- Figures 5B, 6B and 7B appear to have overlapping sections;

- Figures 6C and 7C appear to have overlapping sections.

Additionally, the article shows significant overlap with a number of previously published articles [1-3]. The editors therefore no longer have confidence in the reliability of the data reported in the article.

The authors have not responded to correspondence regarding this retraction notice.
The original article can be found online at https://doi.org/10.1007/ s11033-012-2029-6.

\section{S. Milton Prabu}

smprabu73@gmail.com

1 Department of Zoology, Faculty of Science, Annamalai University, Annamalainagar 608 002, Tamil Nadu, India

\section{References}

1. Muthumani M, Milton Prabu S (2012) Silibinin potentially protects arsenic-induced oxidative hepatic dysfunction in rats. Toxicol Mech Methods 22(4):277-288. https://doi.org/10.3109/15376 516.2011 .647113

2. Renugadevi J, Milton Prabu S (2009) Naringenin protects against cadmium-induced oxidative renal dysfunction in rats. Toxicology 256(1-2):128-134. https://doi.org/10.1016/j.tox.2008.11.012

3. Pari L, Mohamed Jalaludeen A (2011) Protective role of sinapic acid against arsenic-Induced toxicity in rats. Chemico-Biol Interact 194(1):40-47. https://doi.org/10.1016/j.cbi.2011.08.004

Publisher's Note Springer Nature remains neutral with regard to jurisdictional claims in published maps and institutional affiliations. 